\title{
UTVRĐIVANJE KPI I KRITIČNIH FAKTORA USPEHA INTERNE REVIZIJE U ORGANIZACIJI
}

\author{
Nebojša Jeremić, \\ Jovan Bogdanović
}

Telekom Srbija a.d., Beograd, Srbija

\begin{abstract}
Apstrakt:
Cilj ovog rada je da istraži kriterijume kojima se mogu meriti rezultati i učinci interne revizije. Interna revizija koja je nezavisno postavljena u organizaciji, tretira se kao efikasnija, pa samim tim u većoj meri pruža očekivanu korist organizaciji i posledično doprinosi ugledu organizacionih celina. Krajem prošlog veka, u kompanijama se pojavljuju sistemi za merenje performansi koji obuhvataju finansijsku i nefinansijsku perspektivu, kao i dugoročne i kratkoročne predloge za unapređenje. Sistem koji se najčešće koristi za merenje performansi savremenih kompanija je balansirani sistem za merenje performansi i korišćenje indikatora. U radu se kritički analiziraju najčešći ključni pokazatelji učinka (KPI) za merenje revizorskih performansi, koji se koriste u korporativnoj praksi. Aktuelno dinamično okruženje nameće internoj reviziji nove zadatke, i savetodavnu ulogu koja je orijentisana na povećanje dodatne vrednosti kompanija, finansijskih institucija i organizacija, kao i na poboljšanje operativnog poslovanja istih. Upravo je merenje performansi i kvaliteta interne revizije od velikog značaja za efikasno planiranje, unapređenje i kontrolu, kao i za donošenje budućih revizorskih angažmana u savremenim uslovima poslovanja.
\end{abstract}

Ključne reči:

ključni pokazatelj učinka - KPI, ključni faktor uspeha - KFU, interna revizija, efikasnost revizije.
Korespondencija:

Nebojša Jeremić

e-mail:

nebojsaje@telekom.rs

\section{UVOD}

Osnovni cilj interne finansijske kontrole u kompanijama i finansijskim institucijama je da obezbedi da upravljanje i kontrola sredstava budu u skladu sa: propisima, sadržajem budžeta, strateških planova, principima efikasnosti, efektivnosti, ekonomičnosti i transparentnim raspolaganjem sredstvima. Savremeno globalizovano tržište nameće neophodnost da se obezbedi brže i kvalitetnije pružanje usluga, orijentisano ka korisnicima i rezultatima. Poslovni ugled predstavlja condicio sine qua non (uslov bez koga se ne može) savremenog poslovanja. U takvom okruženju svaki rad se ocenjuje, pa je otvoreno pitanje da li neko ocenjuje rad internih revizora, tj. na osnovu kakvih rezultata i pokazatelja interni revizori stiču mesto i ulogu u organizaciji. U najširem smislu posmatrano glavni učesnici korporativnog upravljanja jesu akcionari, menadžment i upravni/izvršni ${ }^{1}$ odbor. Ostale učesnike korporativnog upravljanja čine zaposleni, dobavljači, kupci, banke i drugi kreditori, zakonodavac, regulatorne agencije, okruženje i društvena zajednica uopšte. U radu ćemo pokušati da prepoznamo te pokazatelje. Nastojaćemo da ustanovimo da li je moguće napraviti fino podešavanje ciljnih KPI interne revizije, definisati nove, i redovno ih pratiti kao mogućnost za unapređenje kvaliteta revizorskih angažmana i reputacije u organizaciji.

1 Zakon o bankama i Zakon o privrednim društvima u Srbiji prave razliku u nazivima korporativnih organa. 


\section{MERENJE PERFORMANSI KORPORATIVNOG UPRAVLJANJA}

Uvažavajući brojne definicije i potrebe teorije i prakse, pojam korporativnog upravljanja se može definisati kao mehanizam raspodele prava, obaveza i odgovornosti između upravnog odbora, rukovodstva i drugih učesnika u procesu rukovođenja i kontrolisanja kompanije. Pojam korporativnog uporavljanja je usvojen radi dostizanja njenih ciljeva, u vidu stvaranja pozitivnog finansijskog rezultata, kroz usklađivanje interesa pojedinaca, korporacije i društva. Korporativno upravljanje obezbeđuje strukturu kojom se određuju ciljevi pravnog lica, kao i sredstva za postizanje th ciljeva i praćenje rezultata. U pogledu pitanja odgovornosti učesnika u korporativnom upravljanju, ne postoji jedinstven stav jer se strukture upravljanja i brend pojedinih organizacionih celina razlikuju od države do države, odražavajući kulturne i pravne razlike. Na osnovu navedenog možemo zaključiti da odgovornost menadžmenta i lica zaduženih za upravljanje varira u zavisnosti od zakonskih obaveza određenog pravnog sistema. Praksa pokazuje da su upravni odbor, revizorski odbor, tim izvršnih direktora, tj. menadžment, interni revizori, eksterni revizori i državni organi najvažniji učesnici korporativnog upravljanja. Nakon velikih finansijskih skandala, u kojima je učestvovalo i rukovodstvo pojedinih svetskih kompanija, jača svest da se efektivnost i efikasnost pojedinih organizacionih celina mora stalno preispitivati, jer je odgovornost za sprečavanje i otkrivanje prevara sve veća. Važnost merila za ocenu efektivnosti i efikasnosti interne revizije proističe iz standarda 1311 i 1312, koji sugerišu kontinuiran nadzor kao sastavni deo svakodnevnog nadzora, pregleda i merenja aktivnosti interne revizije. Stalni nadzor je sastavni deo redovne politike i prakse, koja se primenjuje prilikomupravljanja aktivnostima interne revizije i koristi procese, alate i informacije koje se smatraju neophodnim za ocenu usklađenosti s definicijom interne revizije, etičkim kodeksom i standardima. Ocenu efektivnosti i efikasnosti interne revizije mogu da obavljaju kvalifikovani, nezavisni procenjivači ili tim procenjivača koji ne pripada organizaciji. Kvalifikovani pocenjivač ili tim procenjivača mora sprovesti eksterno ocenjivanje bar jednom u pet godina. Kompetentnost procenitelja može biti predstavljena kombinacijom iskustva i teorijskih znanja u dve oblasti: profesionalnoj praksi interne revizije i procesu eksternog ocenjivanja.

Početkom devedesetih godina prošlog veka ${ }^{2}$ pojavljuju se sistemi za merenje performansi organizacije koji pored finansijske obuhvataju i nefinansijsku perspektivu, a u okviru toga dugoročne i kratkoročne mere. Jedan od najčešćih i

2 Za podržavanje strategijskog planiranja ciljeva i resursa, kao i za nadgledanje dostizanja ciljeva u višedimenzionalnom sistemu javnih nosilaca zadataka u domenu preduzeća već godinama je uspešno postavljen koncept sistema izbalansiranih pokazatelja (Balanced Scorecard - BSC ili sistem uravnoteženih pokazatelja je model koji su 1992. godine razvili profesori Kaplan i Norton, više o samom konceptu pogledati na: www.bscol.com). najpoznatijih sistema za merenje performansi je sistem uravnoteženih pokazatelja (Balanced Storecard, $u$ daljem tekstu: BSC). BSC je sistem koji prevodi misiju i strategiju organizacije u merljive ciljeve i pokazatelje kroz nekoliko osnovnih perspektiva: finansijsku, oblast internih procesa, oblast koja se odnosni na korisnike i učenje i rast. Cilj ovog rada je da ukaže na značaj pokazatelja kojim se najvernije reprezentuju performanse svake od navedenih perspektiva, koje će se potom iskoristiti u internoj reviziji. Najprostije rečeno, KPI omogućavaju sagledavanje performanse u prošlosti, sadašnjosti, i što je najvažnije u budućnosti.

Ključni indikatori performansi (Key Performance Indicators, u daljem tekstu: KPI), u svom nazivu imaju pridev „ključni“ što ukazuje na potrebu da se vodi računa o optimalnom broju tih indikatora, koji bi što manjim brojem trebalo da iskažu sve što je potrebno. Nudurupati et al. (2007) pored termina KPI u upotebu uvode i termin KPO (Key Performance Outcomes). Naime, dok KPI meri performanse procesa i daje prostor za preduzimanje korektivne aktivnosti, dakle usmeren je na budućnost, s druge strane KPO je rezultat završenih procesa i aktivnosti, pa samim tim neomogućava promenu ishoda.

\section{PREGLED RAZLIČITIH PRAKSI MERENJA KVALITETA INTERNE REVIZIJE}

Kompanije koje su autsorsovale pojedine poslovne funkcije, u praksi zaključuju prilično kratke rokove (npr. šest meseci), kojima vrednuju koliko efikasno funkcionišu autsorsovane delatnosti (Smith et al., 2005: str. 436). Kao primer navodimo britansku univerzitetsku bolnicu sa preko 5000 zaposlenih i godišnjim budžetom od 170 miliona funti, koja je autsorsovala funkciju nabavke, i uspostavila uzak opseg KPI, koji se koristi u proceni portfolija dobavljača:

1. Higijenski standardi,

2. Brzina/vreme odgovora na ad hoc zahteve,

3. Nedeljni broj osnovanih žalbi,

4. Poštovanje normative,

5. Poštovanje politika i procedura bolnice,

6. Utisak i komunikacione veštine osoblja dobavljača.

Merenje performansi i kvaliteta interne revizije je od velikog značaja za efikasno planiranje, unapređenje i kontrolu, kao i za donošenje budućih odluka. Naravno, analogija važi i za sve organizacione celine, pa se tako dolazi i do metričkog aparata za merenje ugleda svake pojedinačne organizacione celine. Korporativni organi, kao najviši nivo rukovodstva definiše ciljeve i kritične faktore uspeha (Critical Success Factors - CSF) koje organizacija mora da ostvari da bi ispunila svoju misiju. Ovi faktori su dovoljni, da bi se ispunila misija, a koriste se i za identifikaciju ključnih poslovnih procesa organizacije. Upravljanje poslovnim procesima (Business Process Management - BPM) definiše ciljeve ključnih poslovnih 


\begin{tabular}{|c|c|c|}
\hline $\begin{array}{c}\text { Balanced Storecard } \\
\text { pokazatelji }\end{array}$ & Poslovni ciljevi & Key Performance indikatori predlozi \\
\hline \multirow{2}{*}{$\begin{array}{l}\text { finansijski } \\
\text { pokazatelji }\end{array}$} & $\begin{array}{l}\text { poboljšanje } \\
\text { finansijskog rezultata } \\
\text { kompanije }\end{array}$ & $\begin{array}{l}\text { vrednost uočenih poboljšanja iskazanih kroz prihod ili procenat prihoda } \\
\text { vrednost ušteda koje su ostvarene kroz implementaciju preporučenih mera IR } \\
\text { procenatizveštaja sa kojima su organizacione celine saglasne } \\
\text { procenatimplementiranih preporuka }\end{array}$ \\
\hline & $\begin{array}{l}\text { povećati obim } \\
\text { preporuka koje su } \\
\text { implementirane }\end{array}$ & $\begin{array}{l}\text { broj preporuka koje su implementirane uz podršku interne revizije } \\
\text { broj ponovljenih nalaza (nerealizovane preporuke) } \\
\text { broj poslatih follow up na koje se dobio odgovor } \\
\text { broj oblasti povišenog rizika koje su predmet revizije u tekućoj godini } \\
\text { broj uočenih Fraudova }\end{array}$ \\
\hline \multirow{2}{*}{$\begin{array}{l}\text { oblast internih } \\
\text { procesa }\end{array}$} & $\begin{array}{l}\text { realizovan godišnji } \\
\text { plan revizije }\end{array}$ & $\begin{array}{l}\text { broj itera cija sa Odborom za reviziju } \\
\text { procenat realizacije pla na revizije u predviđenom roku } \\
\text { broj izvršenih revizija u odnosu na plan } \\
\text { broj komentara klijenta revizije i odbora za reviziju na izveštaje }\end{array}$ \\
\hline & $\begin{array}{l}\text { viša efikasnost } \\
\text { internih procesa }\end{array}$ & $\begin{array}{l}\text { prosečan broj dana trajanja revizije } \\
\text { prosečan broj sati revizije po zaposlenom internom revizoru } \\
\text { prosečan broj poslatih follow up u odnosu na planiran broj }\end{array}$ \\
\hline \multirow{2}{*}{$\begin{array}{c}\text { oblast koji se } \\
\text { odnosi na korisnike }\end{array}$} & zadovoljniji korisnici & $\begin{array}{l}\text { klijenata } \\
\text { zadovoljstvo korpora tivnih ogana i odbora pla nom revizije - broj iteracija } \\
\text { redovnost izveštavanja korporativnih organa i odbora }\end{array}$ \\
\hline & unapredi transfer & broj sati podrške na implementaciji preporuka \\
\hline
\end{tabular}

procesa, u odnosu na ključne faktore uspeha, koji moraju da se prate merljivim ključnim indikatorima performansi. Poboljšanje ključnih poslovnih procesa se može postići, ako se ciljevi mogu meriti pomoću KPI. Pojedine kompanije koje su implementirale ERP rešenja, kao što je SAP, automatizovale su većinu kontrola, pa je i uticaj IT revizora značajniji. Istraživanja (Miklos et al., 2012: str. 270, 275), uz naravno rezerve da im je uzorak nedovoljno širok i reprezentativan, potvrđuju da su retki primeri kompanija koje su značajno razvile revizorske tehnike i koje raspolažu iskusnim IT revizorskim osobljem.

Važnost indikatora koji ukazuju na učenje i kontinuiranu edukaciju, ne treba ograničiti samo na interne revizore, već je u ovaj proces potrebno uključiti sve učesnike korporativnog upravljanja, tj. celokupni menadžment, kako bi se povećao nivo svesti o kontroli, rizicima i načinu delovanja na različite oblike internog nadzora nad poslovanjem organizacije. Samo uspešno postavljen i adekvatan sistem internih kontrola obezbeđuje uspešan rast i poslovanje organizacija. Poljski istraživači (Grenčík \& Legát, 2007: str. 39) ukazuju da značaj indikatora leži u njihovom progresu tokom određenog vremena, a da posebnu upotrebnu vrednost dobijaju posle implementacije nove strategije, istovremeno uvažavajući značaj ISO 19011 standarda. Naime, taj standard se primenjuje na sve kompanije i finansijske institucije koje sprovede kako internu tako i eksternu proveru sistema menadžmenta. Internim revizorima kao i compliance funkciji je daleko lakše da sprovode revizorske angažmane u organizacijama čiji se korporativni organi rukovode programom provere, pa pored navedenog standarda implementiraju i ISO 31000, koji postavlja smernice za menadžment rizikom. Svakako ISO 9001 je najpopularniji svetski standard za menadžment kvalitetom, a u praksi ga koriste brojne organizacije, bez obzira na veličinu i delatnost. Kako je zasnovan na procesnom pristupu, uz kontinuirano poboljšanje procesa, interni revizori u mišljenjima neretko ističu da primena standarda može da dovede do veće efikasnosti, uštede resursa i povećanja profita ${ }^{3}$. Indikatori koji mere stepen zadovoljstva klijenata revizije, se najčešće dobijaju putem upitnika koji se po obavljenoj reviziji šalje korisnicima. Ipak praksa jedne organizacije iz Brizbejna u Australiji pokazuje da se upitnik mora slati kako klijentima, tako i komisiji za reviziju4.

U istraživanju koje su zajedno sprovodile američko-kanadska konsultantska kuća Protivi Knowleadgeleader i CIA institut tokom 2010. godine), dat je pregled ocene rada interne revizije u pojedinim velikim kompanijama i finansijskim institucijama. Generalna je ocena da se pojedini indikatori ponavljaju, dok su za pojedine kompanije navedeni specifični metrički sistemi za ocenu učinka koji se retko sprovode u praksi:

- Funkcionalni KPI - ušteđeni novčani tokovi, što je veoma teško merljivo u praksi (primedba autora NJ),

- Broj obučenih i edukovanih internih revizora, broj ključnih veština kojim su ovladali revizori,

- Broj diskusija i iteracija sa klijentima,

- Procenat realizovanog plana,

- Prosečna dužina revizije (broj čovek dana),

- Procenat prihvaćenih revizorskih preporuka,

3 http://www.iss.rs/la/button_102.html

4 http://www.financepractitioner.com/contentFiles/QF01/ g6nqgqq7/1k/0/how-can-internal-audit-report-effectively-to-itsstakeholders.pdf strana 6 
Finansijske institucije (SPB Spectrum Brands Holdingsfinansijski konsalting, Commonwealth Bank i Deutsche Bank)

- Evaluacija zadovoljstva menadžmenta, tj. klijenata i korporativnih organa sa radom i nalazima IR, merenje zadovoljstva klijenata posle svake revizije,

- Ispitivanje finansijskog doprinosa izveštaja IR posle implementacije svake preporuke,

- Globalna analiza doprinosa IR organizaciji, u smislu smanjenja troškova i unapređenja upravljanja rizikom,

- Fidbek klijenata (npr. popunjavanje upitnika od strane klijenata organizacione celine u banci),

- Interno samoocenjivanje nakon izvršene revizije,

- Napravili su sistem uravnoteženih pokazatelja koji je usklađen sa strategijom Deutsche Bank, a analiziraju se ljudi, procesi, finansije i usluge,

- Izveštavanje korporativnih organa i komisije za reviziju u skladu sa godišnjim planom.

Realni sektor privrede (SAP - finansijsko softverska delatnost, Shell - naftna industrija i Talecris Biotherapeutics)

- Analiziraju se troškovi revizije i svakog angažovanja,

- Analiza i poređenje revizorskih izveštaja po geografskim regionima,

- Naknadna analiza po završenoj reviziji,

- Progres u implementaciji nalaza,

- Tradicionalne stavke kao što je uveravanje da su IR u skladu sa budžetom, produktivnošću i kvalitetom,

- Evaluacija godišnjeg plana,

- Broj prihvaćenih nalaza i preporuka,

- Evaluacija organizacionog kontrolnog okruženja u prihvatanju internih kontrola.

Efikasan javni nadzor revizijske profesije je bitan element u održavanju i povećanju poverenja u brend revizije. U oblasti zakonske revizije na nivou Evropske unije, 2006. godine doneta je Osma direktiva (2006/46/EC). Kompleksna implementacija rešenja sadržanih u ovoj direktivi zahtevala je izradu posebnog Zakona o reviziji. Cilj eksterne revizijeje da korisnicima finansijskih informacija pruži reviziju visokog kvaliteta, dok predmet interne revizije obuhvata širi opseg aktivnosti. Članom 20. Zakona predviđeno je da društvo za reviziju koje obavlja reviziju društava od javnog interesa dužno je da u roku od tri meseca od isteka kalendarske godine objavi godišnji izveštaj o transparentnosti koji sadrži između ostalog i opis internog sistema kontrole kvaliteta društva za reviziju, kao i izjavu uprave o njegovoj efikasnosti. Stoga je potrebno razmotriti percepciju različitih grupa korisnika revizijske profesije i poverenje javnosti ili drugih organizacionih celina u verodostojnost i brend revizijske profesije. Uspostavljanje odgovarajućeg mehanizma nadzora u reviziji snažno doprinosi verodostojnosti revizijske profesije. Iako je nužno da nadzor prvenstveno sprovodi sama profesija, konačna odgovornost za savesno obvljanje revizorskih zadataka, s dužnom pažnjom i uz potpunu nezavisnost, ostaje na Komisiji za re- viziju. Ipak, brend interne revizije unutar organizacije, može biti i eksterno ocenjen. Naime, svi aspekti poslovanja postaju regulisani, što utiče na značaj tržišno regulatornih agencija i komora. Navedena tela, uz profesionalna računovodstvena tela, sa svojim statutarnim obavezama da zaštite javnost, imaju sve važniju ulogu u regulisanju profesije. Zbog svoje uloge $\mathrm{u}$ funkcionisanju finansijskog tržišta, regulatorne agencije imaju odgovorne obaveze u nadgledanju i disciplinovanju, pre svega, eksternih revizora.

Brojna su akademska istraživanja o proceni kvaliteta revizije, uglavnom eksterne (npr. opširna sistematizacija radova je prikazana u radu Knechel et al., 2013). Istovremeno, srpsko zakonodavstvo nastoji da proceni učinak nekih profesija (Pravilnik o kriterijumima, merilima i postupku za ocenjivanje rada sudijskih pomoćnika Sl. glasnik RS br. 32/16; Uredba o korektivnom koeficijentu, najvišem procentualnom uvećanju osnovne plate, kriterijumima i merilima za deo plate koji se ostvaruje po osnovu radnog učinka, kao i načinu obračuna plate zaposlenih u zdravstvenim ustanovama Sl. glasnik RS br. 100/11, 63/12, 101/12, 46/13; Pravilnik o kriterijumima i merilima vrednovanja rada javnih tužilaca i zamenika javnih tužilaca Sl. glasnik RS br. 58/14 ili Pravilnik o kriterijumima, merilima, postupku i organima za vrednovanje rada sudija i predsednika sudova Sl. glasnik RS br. 81/14, 142/14, 41/15, 7/16). Istraživanje koje su tokom prve polovine 2012. godine sprovele kompanije Ernst \& Young i Forbs na uzorku kompanija koje imaju konsolidovani prihod veći od 500 miliona USD, i diversifikovan prihod u 26 industrijskih centara, pokazalo je da samo 18\% rukovodioca interne revizije koristi KPI.

Ključni pokazatelj učinka ponderisani su sledećim redosledom.

Ključni faktor uspeha interne revizije i drugih organizacionih delova, predstavljaju mere koje izražavaju ciljeve upravljanja, i omogućavaju merenje strateških performansi. Samim tim, svaki proces bi trebalo kvantitativno meriti sa jednim ili dva indikatora koji karakterišu suštinu njegovog rada.

Procena radnog učinka omogućava da se:

- Obezbedi relevantna povratna informacija o učinku za zaposlene, kako bi se unapredio njihov učinak,

- Utvrdi individualni doprinos zaposlenih ostvarenju strateških ciljeva,

- Definišu obrazovne i razvojne aktivnosti, na individualnom nivou ili na nivou organizacije,

- Dobiju relevantni podaci za donošenje odluka o napredovanju zaposlenih, na osnovu rezultata procene učinka,

- Obezbede uslovi za planiranje broja revizora, kao i za sukcesiju na strateški važnim pozicijama,

- Redefiniše proces regrutovanja i selekcije unutar organizacije, odabirom kandidata na osnovu posedovanja odgovarajućih stručnih znanja potrebnih za konkretno radno mesto. 


\section{Ernst \& Young istraživanje iz 2012. godine}

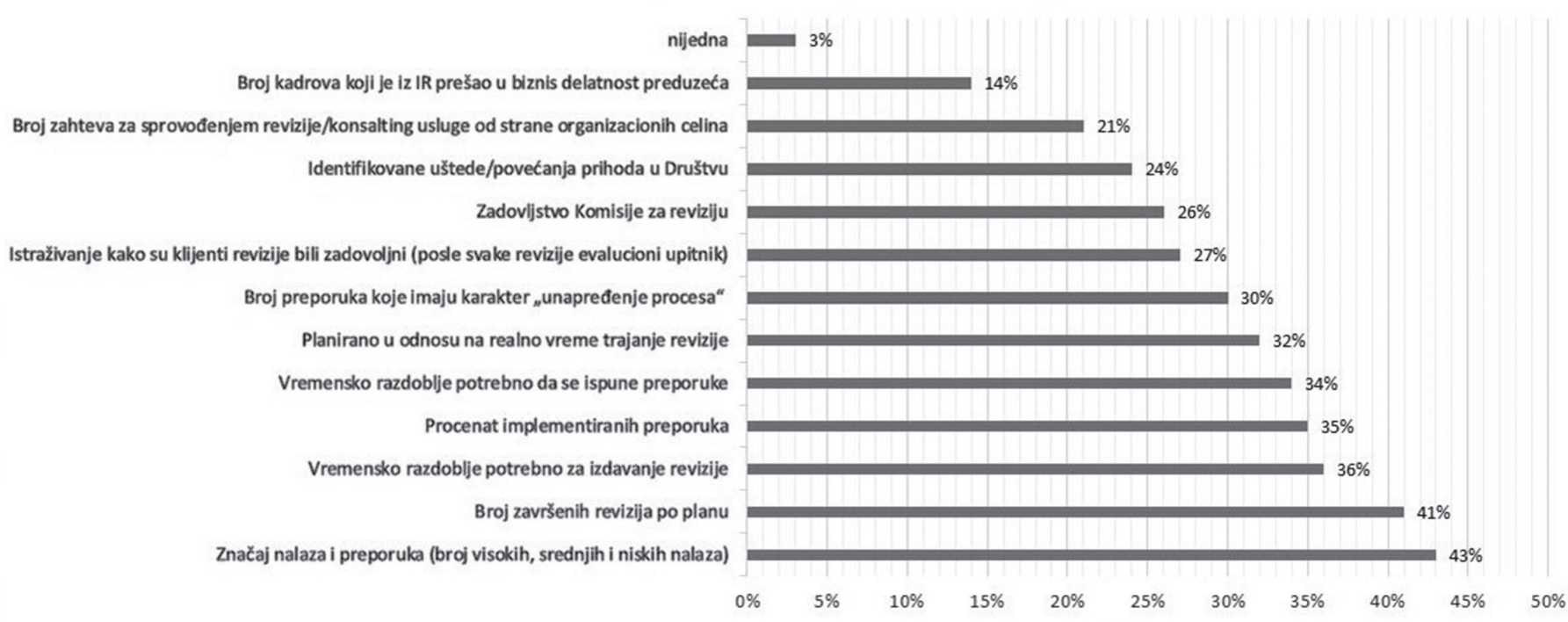

Izvor: http://www.ey.com/GL/en/Services/Advisory/The-future-of-internal-audit-is-now---Run-internal-audit-like-a-business

Neosporno je da se tu kriju zamke, npr. kad treba meriti rad računovođe koji knjiži sudske takse i poistovetiti ih sa brojem proknjiženih transakcija drugog računovođe koji npr. knjiži uvoz skupe opreme, i svih izazova koji prate knjiženje devizne transakcije, špedicije, amortizacije, brojnosti računovodstvenih isprava i dr. transakcije. S druge strane, svima je jasno da je lakše meriti učinak šalterskog službenika, radnika na proizvodnoj traci, i drugih niže obrazovnih profila, nego učinak internog revizora. Cilj svakog rukovodioca je da, na kraju posmatranog perioda, prepozna nivo uspešnosti zaposlenog u ostvarivanju postavljenih ciljeva; stepen ispoljavanja kompetencije; kao i oblasti koje treba da usavršava, kako bi bio uspešniji na datoj ili na nekoj budućoj poziciji. Procenjivač ima nimalo lak zadatak da integriše sve podatke u vezi sa realizacijom učinka u periodu procene i formira odgovarajuće ocene po svim segmentima procene. Australijski PWC je konstatovao u svom istraživanju (2011) da se ugled i KPI gradi na osnovu odnosa sa ključnim činiocima u organizaciji i njihovih očekivanja:

- Da li su pojedine poslovne oblasti bile podvrgavane reviziji,

- Povratne informacije o zadovoljstvu revizorskim timom ili

- Vrednosti unapređenja procesa koje je IR prepoznala, a menadžment implemetirao.

\section{ZAKLJUČAK}

Uspešnost eksternih revizora se može meriti praćenjem berzanskih podataka, objavama bankrotstva i stečaja, odlukama da se kupuju ili prodaju delovi preduzeća, a svakako ne treba zanemariti ni akademsku zajednicu koja je to pitanje aktivno istraživala. Ovaj rad je pokušao da ukaže na načine merenja efikasnosti interne revizije, čiji izveštaji i rad nisu javni pa samim time ni lako merljivi. Ključni poslovni procesi, njihovi ciljevi, rezultati ključnih performansi i ključni indikatori performansi predstavljaju veoma važne faktore uspeha, koji treba da budu pažljivo procenjeni, praćeni i unapređeni. Monitoring i evaluacija KPI otkriva odstupanja između planiranih i ostvarenih vrednosti i pomaže da se potencijalni problemi i pitanja identifikuju i koriguju. Kako bi se obezbedila platforma za analizu specifičnih ciljeva, vrednovanje i poboljšanje, neophodno je meriti ključni pokazatelj učinka. Nedostatak odgovarajućih pristupa za merenje efikasnosti u internoj reviziji je jedan od glavnih motiva ovog rada. Dok je u eksternoj reviziji nešto bolje stanje, jer regulatorne agencije i profesionalna revizijska tela najčešće imaju daleko razvijeniji sistem alata, koji obezbeđuje potpunu nezavisnost eksternih revizora i pažljivo izvršavanje zadataka. Razvijene tržišne ekonomije nemaju uvek adekvatne sisteme kontrole kvaliteta revizora, a kamoli zemlje koje imaju kratku istorijukorporativnog upravljanja, poput Srbije. Da bi se obezbedila kvalitetna revizija, pa samim tim i prepoznatljiv brend, stožer i čuvar zakonitosti poslovanja u kompaniji, potrebno je istražiti kako sistemi kontrole kvaliteta revizije deluju u praksi. U ovom radu, dat je predlog definisanja ključnih indikatora u oceni kvaliteta rada IR. Predloženi model je pogodan kao alat za donošenje odluka o efikasnosti ključnih poslovnih procesa u svim organizacijama, bez obzira da li su iz finansijskog ili realnog sektora privrede. Istovremeno, predloženi model može koristiti top menadžment, revizijski odbor ili direktor interne revizije kao sredstvo za podršku prilikom donošenja odluka u oblasti procene kvaliteta procesa IR; kao sredstvo za procenu vrednosti različitih KPI i njihove analize; ili kao sredstvo poređenja i poboljšanja. 


\section{LITERATURA}

Boța-Avram, C., Popa, I., \& Ştefãnescu, C. (2010). Methods of measuring the performance of internal audit. Annals of the Ştefan Cel Mare University of Suceava: Fascicle of the Faculty of Economics and Public Administration, 10, 137-146.

Cox, A. (2016). How Can Internal Audit Report Effectively to its Stakeholders? Preuzeto 15. 08. 2016. sa http://www.financepractitioner.com/contentFiles/QF01/g6nqgqq7/1k/0/howcan-internal-audit-report-effectively-to-its-stakeholders.pdf

Ernst \& Young. (2012). Our global internal audit survey results confirm that the future of internal audit is now. Preuzeto 15. 08. 2016. sa http://www.ey.com/gl/en/services/advisory/thefuture-of-internal-audit-is-now---adding-value

Grenčík, J., \& Legát, V. (2007). Maintenance audit and benchmarking-search for evaluation criteria on global scale. Maintenance and Reliability, 3(35), 34-39. doi:10.17531/ein

Institut za standardizaciju Srbije. (2015). Standardi sistemi manadžmenta. Preuzeto 15.08. 2016. sa http://www.iss.rs/la/ button_102.html

Nudurupati, S., Arshad, T., \& Turner, T. (2007). Performance measurement in the construction industry: An action case investigating manufacturing methodologies. Computers in Industry, 58(7), 667-676.
PricewaterhouseCoopers. (2011). Maximising Value. Preuzeto 15. 08. 2016. sa http://www.pwc.com.au/assurance/assets/ Maximising-Value-who-dares-wins-Sep11.pdf

Robert, K. W., Krishnan, G. V., Pevzner, M., Shefchik, L. B., \& Velury, U. K. (2013). Audit quality: Insights from the academic literature. Auditing, 32, 385-421. doi:10.2139/ssrn.2040754

Službeni glasnik Republike Srbije. (2013). Zakon o reviziji. Sl. glasnik RS, br. 62/2013.

Smernice za primenu, kao deo Međunarodnog okvira profesionalne prakse The Institute of Internal Auditors, Inc., 247 MaitlandAve., AltamonteSprings, FL 32701-4201, SAD.

Smith, J. A., Morris, J., \& Ezzamel, M. (2005). Organisational change, outsourcing and the impact on management accounting. The British Accounting Review, 37(4), 415-441.

Vasarhelyi, M. A., Alles, M., Kuenkaikaew, S., \& Littley, J. (2012). The acceptance and adoption of continuous auditing by internal auditors: A micro analysis. International Journal of Accounting Information Systems, 13(3), 267-281.

\section{DETERMINATION OF KPI AND CRITICAL SUCCESS FACTORS OF INTERNAL AUDIT IN THE ORGANIZATION}

\section{Abstract:}

The purpose of this paper is to examine the criteria for measuring the results and effects of internal audit. Internal audit which is independently and functionally set in the organization is perceived as more efficient, and therefore it provides greater benefits to the organization and reputation among other organization units. At the end of the last century performance measurement systems having both financial and non-financial perspective appeared in the companies. They also contained long-term and short-term suggestions for improvement. In modern companies the most common system for measuring performance is a balanced system for measuring performance and the use of indicators. The paper critically analyzes the most common KPI for measuring the audit performance which are used in corporate practice. Dynamic environment imposes new tasks on internal audit, as well as the growing advisory role which is oriented to increasing added value to companies, financial institutions and organizations, and improvement of their operational business. Performance measuring and the quality of the internal audit is of great importance for the effective planning, improvement and control as well as bringing the future audit engagements in the modern business environment.

\section{Keywords:}

KPI,

CSF,

internal audit, audit efficiency. 